\title{
Identity and the Evolution of Institutions: Evidence from Partition and Interwar Poland
}

\begin{abstract}
This paper advances a logical, if possibly controversial, thesis: institutional design is inherently a product of identity, at both the individual and group level. Building on recent advances in identity economics and new institutional economics, this research shows how identity can be used to explain institutional genesis and the persistence of "inefficient" institutions. Applying this model to Poland in the $19^{\text {th }}$ and early $20^{\text {th }}$ centuries, it is evident that the identity-based institutional building which had served individuals so well under occupation in Poland resulted in "inefficient" institutions, unsuited for the changing external environment. Only taking an identity lens to the Polish experience can we see a satisfactory explanation for the failure of institutions in interwar Poland.
\end{abstract}

Keywords: identity economics, institutions, Poland, institutional change

JEL Codes: B52; N43; Z13 


\section{Introduction}

The issue of identity economics has been pushing its way into the forefront of the economics literature over the past decade and a half, led by Akerlof and Kranton (2000) and Henrich (2000) and further refined by Davis $(2007,2011,2015)$. In its original incarnation, as in Akerlof and Kranton, this approach posits identity as an additional attribute of a neoclassical utility function, with "identity" generally understood as "the need for a sense of who one is... self-schemas [which] include organized knowledge about one's self [such as] the characteristics, preferences, goals, and behavior patterns we associate with ourselves," (Howard 2000:367-368). By incorporating a person's individual sense of self into economic decision-making, one could better understand not only the source of individual preferences, but also how different utility-maximization strategies were reached (including those that do not appear fully "rational"). Further developing this idea, Akerlof and Kranton (2005:11) expand identity economics to encompass the economics of organization, arguing that "identity is an important supplement to monetary compensation" and suggesting how organizational incentives could be designed in order to incorporate identity concerns.

In the intervening years, the Akerlof and Kranton conception of identity economics has been challenged on a number of its assumptions, leading to a somewhat schizophrenic split in the discipline's views on identity. A different path was outlined by Davis (2007) and developed in subsequent work, a path that focused less on neoclassical ideas of utility and more on social identities and their intersection. Under this alternate conception, "there is an interactive reciprocal relation between the self and society in the sense that each influences the other," meaning that "individuals have personal identities as well as social identities, and these two types of identities need to be seen as related" (Davis 2007:355). This approach to identity, grounded in a more sociologically-oriented framework, means that "individuals act 
as representative agents of social groups," noting however that individuals are comprised of a collection of social identities which are ordered and ranked due to social conflict (Davis 2014:3).

A common trait in both strands of the identity economics literature has been its focus, thus far, on the microeconomic level, explaining the economic behavior of individuals either in relation to their own identities or as a function of their social groupings. Missing from the identity economics research has been more macro-oriented analyses, moving beyond small- or narrow-group orientation to understand society-wide behavior and mechanisms (van den Bergh and Gowdy [2009] is a notable exception). The reason for this current focus can be traced to the grounding of both strands of identity economics in socially-oriented disciplines outside of economics, either social psychology (Akerlof-Kranton) or sociology (Davis). In regards to social psychology, the discipline as a whole has limitations in moving beyond group dynamics (see Jost et al. 2004 for an example of such theoretical difficulties), and reliance on social psychology has inhibited the development of a view focusing on the aggregation of individual and social identities into the underlying machines of economic systems, institutions. While sociology has a more-developed framework in understanding institutions, identity economics has not yet incorporated these insights into fashioning a theory of institutional influence. Indeed, in both the social psychological and the sociological approach, institutions are either treated as exogenously given - and thus merely an external factor that plays a role in shaping identity - or as a manifestation of various power structures that can be changed - but with no theory on how such change occurs.

Despite not yet broaching the gap between identity and institutions, identity economics has laid a solid foundation for developing such a theory of institutional change, a foundation which can be built upon using the insights of new institutional economics (NIE). The NIE literature has grappled with the idea of how institutions come to be or why they change, relating institutional processes to both calculations by 
individuals and in terms of social identities. Van den Bergh and Gowdy (2009) note that most theories of institutional change are lacking ideas of identity, and instead make recourse to ideas of efficiency and utility, but this is not uniformly the case. North (1999), in particular, showed institutions as mechanisms created to structure the environment, implicitly noting that these mechanisms both are derived from individual preferences but also act to socially reduce the set of available choices in order to encourage decision-making. Work from Mijiyawa (2013), examining the genesis of property rights, also lays out theories of institutional formation that emphasize, both at the individual and national level, the social identity of a country's citizens.

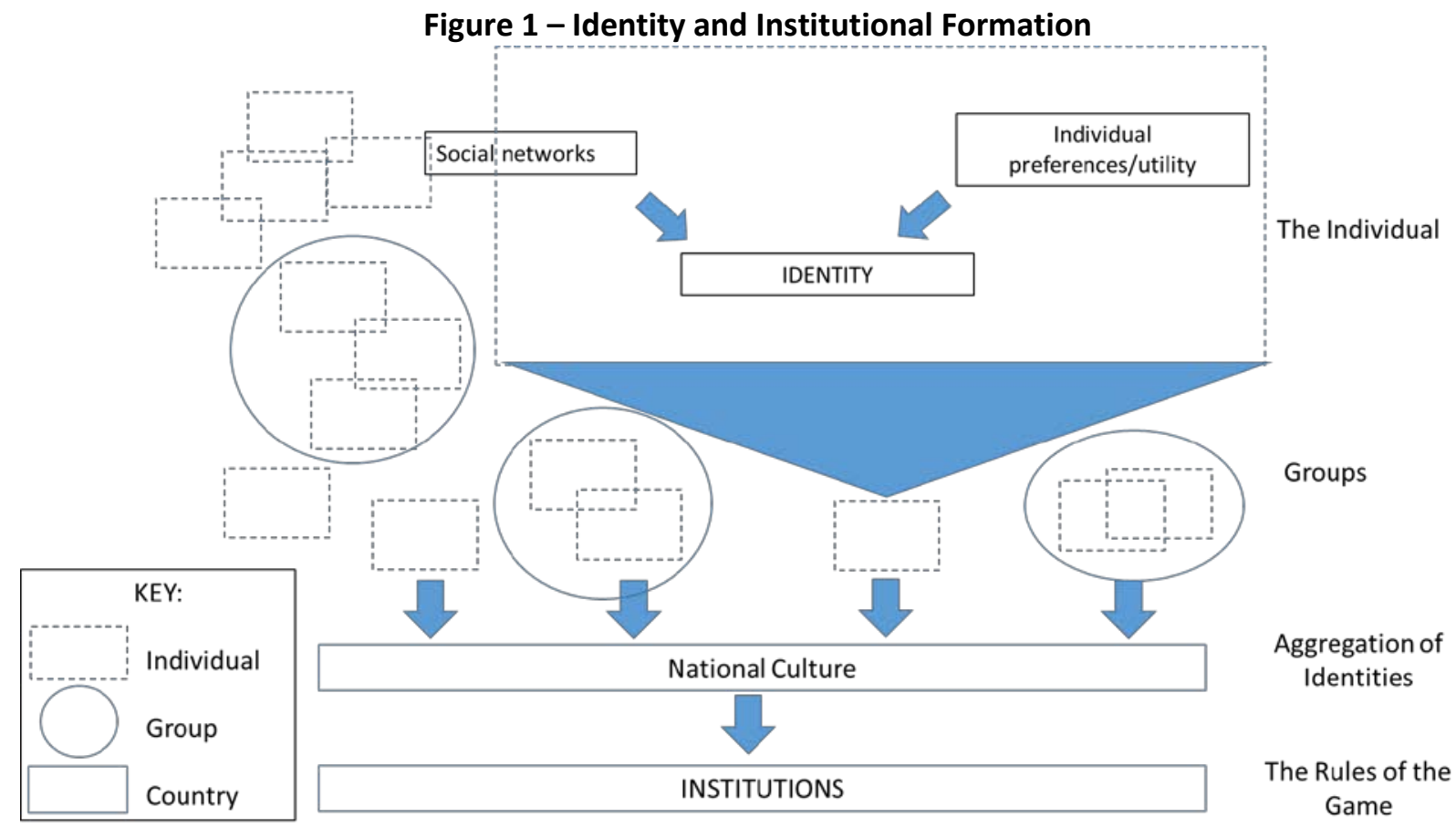

In fact, institutions, as rule of the game and as mediating mechanisms for human action, may play the same role at the national level that identity does for an individual, creating "a capability for maintaining and developing an account of oneself in changing interactions with others" (Davis 2011:188, in reference to identity); in this sense, institutions serve as the manifestation of identity of a nation, aggregating up from various individuals, social networks, groups, and national culture but creating a new object that may be larger than the sum of its parts (Figure 1). ${ }^{i}$ This particular trait means that attempts 
to influence institutions would have to go through the personal and social identities of citizens and their constituent groupings (Simon and Klandermans 2001): as Akerlof and Kranton (2000) briefly note, political leaders often seek to change population preferences through changes in identity, both personal and social, a shift which can then translate to changes in the composition of political and economic institutions in a country.

Given this reality, this paper advances a logical, if possibly controversial, thesis: namely that institutional design is inherently a product of identity, at both the individual and group level. Put another way, if identity is a crucial determinant in our preferences, our utility maximization, or our social relations, then not only would public policies follow from these sense of self, but also the institutions used to mediate interactions with others, whether personal (political institutions) or impersonal (economic institutions). This research takes up the challenge of Huettel and Kranton (2012:681), who note that identity economics should "provide a bridge to research in mechanism design and institutional economics, which now considers how social structures (e.g. legal systems and cultural norms) shape how economic institutions and societies develop." Indeed, institutions in a society would reflect shifting ideas of

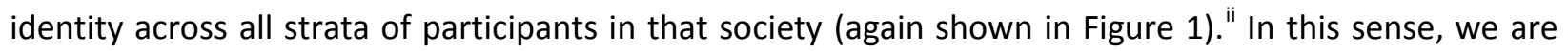
taking one step back from Bowles' (1998) and Akerlof and Kranton's (2005) assertion that organizations and economic institutions in particular shape motivations and values, to argue that, yes, this is true, but these institutions only came about because of various individual perceptions of identity (an assertion closer to Davis' [2014] argument on social identities). In fact, we are taking a much further step back to some of the tenets of the "original" institutionalists such as Wesley Mitchell, who wrote "that the changes in human life are due mainly to the evolution of culture" and so economists should "concentrate their studies to an increasing degree upon economic institutions -the aspect of culture which concerns them" (Commons 1925:8). 
Seen through an identity lens, institutions do not arise in a vacuum, and while institutional evolution may be path-dependent, institutional genesis is heavily reliant on identity; as an example, Grosfeld et al. [2013] note that identities derived from segregation in the Pale of Settlement (the only part of the Russian Empire where Jews were allowed to settle after 1791) have led to persistent anti-market sentiments and, presumably, institutions. While such an assertion of identity leading to institutions may be a bit "chicken and egg," to assume that causality runs only from institutions to identity is to miss the genesis of institutions themselves. Simply put, if institutions are the "rules of the game," then identity lets us know just which game is being played.

The appealing nature of the approach put forward by this paper is that the framework sketched here is relevant for both sides of the identity economics debate, mainly because institutions themselves are different. While most NIE approaches to institutional formation tend to side more with the Akerlof and Kranton (2000) conception of identity, more mainstream work by authors such as Bisin and Verdier (2001) emphasizes the importance of cultural traits in institutional persistence, placing social identity as a key driver of particular institutions. But by recognizing that institutions themselves are different and have different drivers, including different group dynamics, we can see that there is a role for both utilitarian-based and sociologically-based approaches to identity. Thus, while the debate may rage on what is the main determinant of identity, this paper argues that the individual's conception of identity from both spheres, aggregated across individuals and manifested in dominant social groups, can be shown to be a direct determinant of institutional genesis, persistence, and/or change..$^{\text {iii }}$ In this sense, the precise driver of identity is less important (at this stage) than understanding where identity comes into the institutional process (as shown in Figure 1) and, eventually, what effect it has; from understanding 
the nature of the institution being discussed, we may also tease out which approach to identity economics is more plausible for driving institutional creation. In either case, by introducing identity into the process of institutional formation or change, we may understand why "inefficient" institutions persist (as Acemoglu [2006] modelled), how institutions are selected (van den Bergh and Gowdy 2009), why exogenously-impose institutions may fail to take root, and how it takes changes in identity for the institutions themselves to reform.

As a way to illustrate this concept, this paper utilizes the example of Poland from its historical roots as the Polish-Lithuanian Commonwealth through its Partitions in the $18^{\text {th }}$ century, culminating in its failed experiment in democracy in the interwar period (1918 to 1939). Even under its Partitions, the nation of Poland remained a fairly homogenous entity, inspired by not only a social identity of being Polish, but also animated by its nearly-uniform Catholic heritage and its culture of resistance to outsiders; Poles may have had many selves, but these multiple identities were curiously aligned across individuals and were reinforced by social interaction across various spheres. Throughout Poland's history, but especially when it ceased to be a sovereign entity, this issue of social identity was crucial to both individual identity and the creation of various organizations and institutions to preserve the Polish nation. However, once the country was again independent after the First World War, the identity-based institutional building which had served individuals so well under occupation resulted in "inefficient" institutions unsuited for the changing external environment. Put another way, institutions based on an increasingly-romanticized and anachronistic social identity were ill-equipped to deal with the reality of interwar Europe.

The rest of this paper proceeds as follows: the next section lays out the basic theoretical argument of the relationship between identity and institutions, including showing the relationship between identity and institutional persistence, while Section III goes into depth on the Polish experience of the $19^{\text {th }}$ and 
early $20^{\text {th }}$ centuries. Section IV offers a concluding analysis and agenda for further research in this area, setting out opportunities in both identity economics and NIE to build on this paper.

\section{Identity Economics and Institutional Design: A Basic Framework}

In order to understand the relationship between identity and institutions, it is helpful to understand just what institutions are. Hartwell (2013:17) defines an institution as "a set of rules, constraints, and behavioral guidelines, enforced by either formal or informal means external to the individual, which are designed or arise to shape the behavior of individual actors." This definition that adds to North's shorthand of institutions as "the rules of the game" but also encompasses the work of the "original" institutionalists such as Veblen or Commons, who conceived of institutions as mechanisms of "restraint, liberation, and expansion of individual action" (Commons 1934:73). Institutions may be further defined by their mechanisms (sanctioning or facilitating) and, most importantly, the sphere in which they operate, meaning that an institution may be predominantly economic, political, or social (of course, there may be institutions with effects on more than one sphere, but all institutions operate predominantly in one of these classifications)..$^{\text {iv }}$

The dividing line between these spheres and, thus, different types of institutions, as noted in Hartwell (2013), can be ascertained by the ultimate objective of the institution; while the desired intermediate outcome of behavioral change is uniform across all institutions (i.e. all institutions are predicated on changing behavior), the goal of changing this behavior and to what end differs across various types of institutions. And, of course, given the evolutionary nature of institutions, the objectives of an institution may not necessarily be planned, conscious, or even the same over time. For example, as Hartwell (2013) shows, economic institutions are meant to mediate economic outcomes and alter economic behavior, generally less concerned with other intangible goals such as the distribution of power in a society and 
instead determining incentives and constraints on economic actors (Acemoglu et al. 2005). But whereas (most) economic institutions are focused on altering behavior related to allocation of resources (Acemoglu et al. 2005), the guidelines and constraints of political institutions deal more with distribution of power within a society. Granted, such distribution could be modeled on a utility-maximizing basis, e.g. how to enable the greatest number of people access to the political system, but in general the mechanism of a political institution is to mediate amongst differing interests in a society.

Understanding this demarcation amongst institutions is crucial for introducing the idea of identity as a driver of institutional genesis, mainly because even institutions which have utility-maximization as an avowed goal can be driven by identity in their creation, implementation, adaptation, and persistence. Indeed, by incorporating identity into a theory of institutions, we see that utility can be understood as entering the continuum of institutional creation at a later point than is commonly assumed in much of the mainstream and new institutional economics literature. To further flesh out this argument, assume, as Akerlof and Kranton (2000) assert, that identity determines our preferences, and thus to a large extent our utility-derivation functions. If this is the case, these perceptions of individual utility, shaped by our identity, must be the basis of institutional design, as a mechanism to translate aggregated preferences across a society into an aggregated utility. However, it is crucial to note that the utility facilitated by institutions is at best a second-order effect of institutional mechanisms, as institutions are first and foremost designed or arise to alter behavior, shift incentives, or create constraints. Seen in this light, institutions are thus nothing more than a way to actualize the goals of various social and individual identities, with the construction of such institutions framed in a meta-sense by the identity of participants. Behavioral rules and guidelines are necessarily informed by broader conceptions of identities and the interactions of social groups, it is therefore institutions which transfer these informal rules related to self-perception into formal mechanisms of sanctioning and rewards. 
An example of perhaps the most utilitarian of economic institutions, property rights, may help to illustrate the concept of identity's effect on institutions, rather than the other way around. Property rights are commonly assumed to have a dual purpose of lowering transaction costs (Clague et al. 1996) and preventing objective trespass by others (Hoppe 2006), with the specific implementation of property rights predicated on local circumstances (Agrawal and Ostrom 2001), cultural mores (Szreter 2007), and, as argued here, dominant personal and social identities. Both of the outcomes engendered by the protection of such rights alter economic behavior, but while these rights (presumably) translate into higher levels of utility for the individuals under this regime, this only comes about through the mechanism of incentives and sanctions (which themselves may be related to power structures and legitimacy).

More importantly, the utility that is to be maximized and the incentives behind this concept of utility have already been filtered by the identity of the participants of the property rights regime; that is, the extent of protection of property rights and the manner in which this institution operates is based upon already-existing factors which have been created by identity. In the first instance, national and cultural approaches to property in general determine property rights, but these national approaches are already built upon a foundation of identity and self-perception. It is precisely why early American settlers, seeing themselves as rugged frontiersmen, devised a particular form of property rights (with its own set of rules and norms), while English parishes in the $16^{\text {th }}$ century created a different but similar system at the individual level (Szreter 2007) and the UK created an effective system at the national level in the following century derived from the identity of political leaders (North and Weingast 1989). Secondly, protection of property rights is nested in a country's extent of legal protection more broadly, with the entire idea of what may and may not be legally protected (and to what extent) derived from how 
individuals perceive their identity in relation to others. An illustrative example of this is the idea of "home," which enjoys a favored legal status vis a vis other property in Anglo-American jurisprudence, due mainly to the fact that "ideas like privacy, security, family, and continuity are deeply rooted in the psychology of home" (Barros 2006:257). An identity attached to place thus generates its own legal protection and an institutional mechanism to enforce these protections. Finally, the intersectionality of an individual's identities as an economic being, provider for a family, productive member of a community, or any number of other social identities aggregated together into a greater and perhaps independent national identity also determine how property rights are developed. Is the identity as a provider more important across a majority of citizens (in which case stronger property rights may be enacted), or is the idea of community predominant (meaning that individual rights may be weaker but "community" rights may be stronger, as shown in Ostrom and Hess [2010]?). In sum, institutions such as property rights may influence the identity of the individual (Greif and Laitin 2004), but they come about specifically because of various individual identities. ${ }^{v}$

This insight is more expansive than a simple Marxian analysis of superstructure, nesting the idea of superstructure in a larger relationship between identity and the formation of economic and political relationships within a society. Marx (1859/1979) held that institutions (a portion of the superstructure) were nothing more than an expression of the prevailing power structure derived from relations of production (the base), an analysis which has found some favor in modern economic thinking. However, if identity is both malleable and a determinant of institutional design, then institutions are governed by an aggregation of individual identification, which may shift, and not merely based on monetary (or productive) utility. ${ }^{\text {vi }}$ Power relations may enter into the individual's conception of identity (and thus institutional formation), a point which has already been stressed in other views of the interplay between identity and institution. But identity would also shape the prevailing incentives and sanctions which 
institutions enact, and indeed help to set the power structure; these relations would then create mechanisms which may eventually translate into monetary/productive utility, but such an assumption is not necessary to explain the existence of certain institutions.

Such an idea of how identity relates to power relationships and institutions is in fact closer to the position staked out by the original institutionalist thinkers such as Thorstein Veblen. Veblen's book The Theory of the Leisure Class (Veblen 1899) laid out the supposition that social status was intrinsically connected with how far one was removed from the working classes, and thus various activities (consumption, leisure) were needed to reinforce this distance. As Moran (2014:131) notes, Veblen never actually used the word "identity" in his writing, but "instead identified and analyzed some key social shifts to do with consumption, social class, and the mechanisms of social distinction that would eventually come to be captured... by the idea of identity." While focusing on consumption, Veblen perhaps inadvertently illuminated the reality that identity, or a longing for an external manifestation of an identity which was felt internally, had resulted in the propagation of certain economic institutions and, undoubtedly, power relations expressed through political institutions.

Building on this theoretical basis, the influence of identity on institutions would hold even if we assume away utility entirely, as Veblen did in his analysis of "conspicuous consumption goods" and the materialist impulse to purchase "useless" things in order to reinforce identity (Slater 1997). Such an approach can be seen in the sociological-tinged theories of Davis (2015:1217), where "individuals are directly influential in determining how their social roles play out, this then influences their relational social identities and this then influences the way they regard their categorical identities." As Figure 1 shows, there is not a direct relationship between identity and institutions, as an individual's identity 
passes through, is influenced and influenced by, and is filtered through social networks, groups, and organizations (it also would encompass informal institutions, see below). However, much of the literature taking the sociological or, recently, a stratification approach, has focused on transmission of institutions, as an external social force, on identity; Davis (2015:10) best summarizes this idea when he asserts that "what accordingly determines personal identity in society is partly the choices of individuals, partly the nature of social structure in institutions and organizations as they affect social roles and partly prevailing practices of prejudice and stigmatization employed by dominant social groups."

But while personal identity may be determined by external factors (including groups and institutions), the influence running from identity to institutions may be even more important, as shifting group dynamics can be evanescent without a semi-permanent apparatus (i.e. an institution) to sustain them. From the stratification approach, this "intergroup inequality" may exist at the level of individual identity or even society-wide biases, but the only way in which these hierarchies can persist is if the social perception of identity is perpetuated via specific institutions. In this sense, a socially-powerful group has an incentive to devise mechanisms that reinforce such power imbalances (a point similar to Mijiyawa's [2013] "political approach" to institutional creation), meaning that institutions arise from the wellspring of identity, albeit to advantage the facilitation of one group (or disadvantage another group) rather than merely mediating outcomes. Ironically, as Long (2001) notes, this source of institutional creation may end up driving social networks to be even more detached from formality and indeed create parallel, if informal, institutions (see below), thus driving institutional creation at two separate levels.

It is not only stratification which may drive institutional genesis, however, as shared experiences and identities may have the same effect in forming institutions. Meagher (2005) makes a compelling case regarding social networks in Africa, noting that the particular "institutional practices" embedded in 
social networks can help to understand the evolution of broader, national-level institutions; that is, that the development of national institutions is predicated on the values and legacies of the sub-groups from which they emerged. At an even broader level, a shared national culture may also lead to the creation of certain institutions based on the shared national idea as the dominant social group primus inter pares: Van den Bergh and Gowdy (2009) acknowledge this fact as they highlight the process of group selection as a key channel of cultural transmission, noting that cultural group selection can help to understand why institutions come into being (as well as survive, see below). In that same vein, Gürerk et al. (2006) posit that social group selection, and in particular intra- and inter-group norms, create a competition amongst institutions, with only those in line with the cultural Zeitgeist surviving. Such an understanding of the role of identity in institutional formation also points us to the idea that personal identity, as well as national culture, may change over time, meaning that institutions also need to shift or adapt (a phenomenon we will explore in the next section).

\section{Informal and Formal Institutions}

Thus far, we have explored how identity may influence institutions, understanding that different types of institutions, based on their ultimate objectives, may utilize individual and social identities differently. However, we have not to this point explicitly touched on the horizontal demarcation between formal and informal institutions, a crucial distinction. Generally, those working in identity economics agree with Herrmann-Pillath (2008:22), who asserted that "identities are mainly related with informal institutions, as informal institutions mainly relate to social coordination in groups. In contrast, we can relate the supply and demand of public goods to the formal institutions of a nation." This harkens back to an issue that was raised in the previous section, namely that insights from social psychology and, to a lesser extent, sociology are more comfortable with individual and group dynamics rather than broader societal 
institutions such as an independent judiciary or property rights. However, while informal institutions are closer to the pure aggregation of individual identities, given their small-scale nature, one need not discard the fact that formal institutions as also driven by identity.

Formal institutions derive from both informal institutions and social groupings, as well as conceptions of utility and efficiency, bumping together within a society. Where the idea of identity might be lost is in that fact that formal institutions allow for anonymous interactions, built upon norms that have been established at the informal level of a society but without the necessary interpersonal trust embodied in these smaller-scale interactions. For example, informal financial intermediation, such as small-scale lending or even "loansharking" requires face-to-face interaction, trust, and understanding of the norms of repayment; these interactions in informal financial intermediation are driven by social identities, group identification (especially in regards to compliance), and personal identity regarding one's own trustworthiness as a "financial subject" (Langley and Leyshon 2012). By contrast, formal banking, as Rajan (1998) notes, may substitute in an atmosphere where such trust or even friendly relations do not exist, providing an implicit contract (in the form of deposits) that could not have been engineered at the informal level. By anonymizing the transaction or removing it from broader group dynamics, it can be assumed that identity, at either the individual or group level, has been negated at the level of the formal institution.

Unfortunately, this interpretation is not correct, as the behavior of the clients of the bank is also informed by their understanding of themselves as financial subjects (Langley and Leyshon 2012), a key part of the relationship under the rules of the (financial) game. Perhaps more importantly for our purposes, while the services provided by the bank (contracting in an incomplete-contracting world) may be divorced from the needs of informal institutions, they are never divorced from the larger culture or 
social milieu from which they emerge. Hahn (2014) provides evidence for this reality in regards to the operations of Austrian banks over the past 20 years, showing how cultural proximity (and formerlyshared identities) have influenced their cross-border lending dramatically (this finding was seconded by work from Owen and Temesvary [2015]). Similarly, the sheer diversity of formal financial institutions, not only within countries but across religions and cultures, shows how individual and national identity shape the operations of such institutions (and how deviating from this identity can prove costly for a financial institution, see Haniffa and Hudaib [2007] in the context of Islamic finance).

Indeed, it would be a fallacy to say that formal institutions are wholly separate in terms of identity than informal ones, mainly because there is a wealth of evidence that the success of formal institutions depends on how well they incorporate the identity and culture (Boettke et al. 2008). Indeed, where formal institutions are misaligned with informal ones or if they are exogenously-planted without concern for local identities or culture, we are likely to see the failure of otherwise "successful" formal institutional mechanisms that have worked in different contexts (Guinnane 1994; Roland 2004). In such an environment, it is formal institutions that must yield to not only informal ones, but the identity which reigns supreme in the determination of these informal institutions. To return to the example of property rights, Bubb (2013) shows how social norms at the group level are more important to the development of property rights in many societies than formal legislation, meaning that informal contracting arrangements, informed by identity, determine the actual level of property rights protection in a country rather than laws. In this manner, institutional mechanisms, devised to alter behavior in a different context, may not have the desired effect if they are pushing against identities that are either foreign, less malleable, or opposed to the behaviors desired as an output from the institution. To use our earlier metaphor, the (institutional) rules of the game could be made for chess, but if society sees 
itself playing checkers (draughts) instead, the rules will have little effect on behavior (and, by extension, economic outcomes).

\section{Applications of an Identity Theory of Institutions}

In contradistinction to the failure of "successful" institutions, understanding identity as driving institutional creation at the formal level may also help us to understand the main conundrum of institutional economics: why do "inefficient" institutions survive? While mainstream economics has attempted to model the persistence of institutions that are non-growth enhancing, the explanations offered have also been tied to monetary payoffs and pecuniary incentives. For instance, Acemoglu (2006), to take the most prominent example, models institutions in regards to their ability to generate opportunities for revenue extraction, showing how even growth-dampening institutions can continue to persist if they deliver a payoff to elites. In this world, the preference for inefficient policies by political leaders leads to inefficient economic institutions, or, rather, institutions which may be "appropriate" at one point but, as time passes, become "inappropriate."

The Acemoglu (2006) approach has much to recommend it, especially as it appears to be an accurate sketch of many countries throughout history. However, this approach also has various shortcomings, not least of which it presupposes that there is a definitive "hierarchy of institutions," with political institutions being the wellspring of all other institutions in a society. That is, the Acemoglu approach explains weak political institutions as the cause of institutional malaise across every other institution in a society, a hypothesis that need not always hold (especially given the demarcation of institutions we noted above). In reality, the Acemoglu hypothesis posits only one "inefficient institution," the political system, an institution which is assumed to be motivated by economic incentives, specifically pecuniary 
motivation. Again, as noted above, the distinctive feature of political institutions is that their end goal concerns the distribution of power in society; while this power may be economic as well as political, it is undeniable that other motivations may be behind the acquisition of power. To be glib about it, Hitler wasn't out merely to get rich.

A further, more important critique of the Acemoglu theory is that it misses the reality that inefficient institutions exist which do not rely on pecuniary motivation alone. To return to the example of Nazi Germany, social organizations such as Hitler Youth are "inefficient" in the sense of growth or even racial harmony, but they existed because of different motivations apart from merely economic gain (Voigtländer and Voth 2015). It is here that the idea of identity in the propagation of inefficient institutions begins to emerge; indeed, if, as Akerlof and Kranton (2000) first postulated, identity brings in calculations beyond the realm of the monetary in altering "payoffs," so too could identity result in institutions that appear detrimental due to other "payoffs" related to identity. To put it another way, identity at the individual, social, and national level creates the available space of institutions within a society, with particular institutions arising and their particular implementation or ordering based on additional criteria such as utility or efficiency. Thus, given that institutions are primarily rooted in an individual identity, a social identity, and a national (cultural) identity, considerations such as efficiency may be discarded if the institution is forced to choose between utility and identity. ${ }^{\text {vi }}$

There has already been some exciting research in this vein, reinforcing this point. As noted above, Gürerk et al. (2006) show in the context of sanctioning institutions how institutions in line with national culture or general perceptions of identity continue to persist, mainly because they make recourse to the non-pecuniary benefit of reinforcing identity. Closely linked to this assertion (and to the case of Poland, as shown in the next section), Searle (2005) notes the importance of language in transmitting 
institutional reality; given that language is already circumscribed to a particular group identity, the persistence of language may continue to reinforce institutional forms over time. Similarly, van den Bergh and Gowdy (2009), in the context of group selection, note that institutions may be connected to specific groups and their dynamics (i.e. group identity), and thus persistence of institutions may result from competition amongst groups and the dominance of one group identity over another. Finally, such transmission need not occur at the group level, as Tabellini (2010) formally models the choices a parent might make in transmitting certain aspects of morality, including a desire to cooperate or compete (in a Prisoner's Dilemma setting). This work shows that socialization to a particular identity (e.g. of a cooperative person) takes hold where these norms are already prevalent. In this formulation, institutions based on a certain identity-based conception, such as "I am cooperative," are expected to thrive simply because the norms were already prevalent and the incentives remain to transmit these norms culturally to the next generation.

Moreover, an additional point about institutional change, made by Boettke et al. (2008) and Thelen (2009) in other contexts but applying crucially to the idea of identity leading to institutions, is the matter of time inconsistency. In particular, changes in identity for an individual, for a social group, or for an organization (Empson 2004) may take several years, if not decades; these changes may be predicated on shifting personal circumstances (i.e. an increase in salary as one ages) or roles (becoming a parent or spouse, see Burke 2006) or broader societal shifts (such as the entry of women into the workforce). Moreover, the process of identity change may not be linear, in that it could undergo false starts and dead-ends (as is seen in the vast literature on adolescence, for example Syad and Azmitia [2009]), meaning that the process of identity selection itself may not settle for a long period of time. The point of this digression is to once again highlight the defining feature of institutions, their semi-permanence. But realizing that institutions are derived from identity, which in itself may take years to change, helps to 
explain institutional "stickiness." That is, identity changes may take a long time, and so their filtering through to institutions and thus institutional change would take even longer to occur (especially given that formal institutions are cobbled together from informal norms and values).

This approach to institutional design may also shed light on another question of new institutional economics, mainly "why does an institution which works here doesn't work there?" There is a large literature on the failure of exogenously-inspired or transplanted institutions, putting the blame on their failure squarely on their inability to conform to local norms and values (Dia 1996; Djankov et al. 2003; Dai 2016). The lack of cultural sync between an exogenous institution such as electoral democracy and its transplanted country is a very plausible explanation, given that institutions must bubble up from informal norms and, as has been stressed, identity. Indeed, such a lack of alignment between culture and an externally-inspired institution could strike at the heart of what political scientists term the legitimacy of an institution (Gibson 1989). But if we see institutional transplants through an identity lens, more nuances emerge beyond simply noting that cultural differences cause institutional failure; as Figure 1 shows, national culture is an aggregation of identities, and not every transplanted institution may fail, simply because some institutions are in tune with perceptions of identity at the individual and social level, even if they do not necessarily have the reinforcing norms in place yet. It is in this environment that an exogenously-placed institution could actually succeed and shape behavior successfully going forward, helping to actually form the prerequisite norms and rules for interactions even though they do not exist already, simply because the institution comports with social and individual identities of a nation's citizens.

III. The Effect of Identity on Institution-building: The Experience of Poland 
The previous section has laid out a theory of identity and its influence on economics that seeks to be comprehensive, in that it encompasses many different conceptions of identity, and elegant, in that it provides an explanation for many conundrums in institutional economics (whether or not it succeeds on either count I leave to the reader!). But any theory needs a proving ground on which to test it, and this section attempts to provide such an environment. Indeed, the evolution of institutions in the nation of Poland over its long history provides us with some hard evidence on the role of identity, both in a utilitarian and social group-setting, in shaping national institutions.

The long genesis of Poland's institutions during the Polish-Lithuanian Commonwealth (from 1386 to approximately 1654) appeared to be shaped by utility considerations rather than strict identity ones; indeed, as argued elsewhere (Hartwell 2016a), the theories of Douglass North (1979) furnished an accurate description of the development of property rights in Poland, with the development of the institution owing more to economic considerations rather than one of identity. However, this was mainly due to an important factor, mainly the reality that a "Polish" identity was still being formed from the various local identities prevalent at the time, not least amongst the Polish nobility (the szlachta), who were very focused on their own narrow geographic interests (Hartwell 2016b). Zientara (1974) notes that the identity of Poles was very fluid in the preceding and early years of the Commonwealth, mainly due to the open-door policy of the Kingdom and the large exposure to foreigners, making Poland a mishmash of cultural influences; Tazbir (1982:47) gives further evidence to this effect, stating that "up to the 16th century, the Polish nation was still conceived as a community inhabiting the same territory." Given the lack of a uniform national culture and the comparatively smaller set of social identities available to town- and country-dwellers in $15^{\text {th }}$-century Poland, one can thus examine the development of political, economic, and social institutions in early Commonwealth Poland as being more in line with Akerlof and Kranton's (2000) conception of identity, with the varying social identities of Poles creating 
local institutions which were heavily based on utility rather than broader social group identification or national identity.

These local and narrowly-geographic identities began to shift in the mid- $17^{\text {th }}$ century, due mainly to the external threat which Poland as a country faced (Hartwell 2016b). Almost-continuous war in the $17^{\text {th }}$ century, with occupation by the Swedes and a rebellion from the Cossacks to the east, provoked an existential crisis in the Commonwealth, forging a true national identity and, thus, the development of country-level institutions around this identity. Local schisms between Warsaw, Kraków, and Gdańsk, apparent through previous centuries (Stone 2001) meant differing institutions, driven by different identities: the seafaring traders of Gdańsk were different than the public administration of Warsaw, and saw themselves as such. These differences were mostly set aside under the threat of foreign occupation, with national institutions (including more formalization of national political institutions) being forged under the common identity of "Poland." This common identity was an amalgam of regional identities, but also was a product of its times, an identity of a Poland continually under siege from enemies internal and external. An emergent identity throughout the wars of the mid-1600s onward (Mach 1997), it was confirmed by the late $18^{\text {th }}$ century with the successive Partitions of Poland across three empires (Russia, Prussia, and Austria-Hungary). With the country of "Poland" no longer in existence, but newly-conscious Poles still on the same territory, various social identities were reinforced to set Poles apart from their occupiers, most prominently, the identity of Poland as a Catholic nation, to contrast with Orthodox Russians and Lutheran Germans (Mach 2007).

In fact, the preservation of national identity was the overriding goal of Poland during the Partitions, and formed the basis of the development of informal institutions on the territory of Poland during these 123 years. When besieged from outside, for example, by the Kulturkampf from Prussia which aimed to "de- 
polonise" the country and force Poles off their lands, Poles instead banded together in "self-help" organizations and locally-operated credit unions (Hartwell 2016b). As Blanke (1974:552) noted, "In some ways the Kulturkampf experience actually aided the Polish cause, e.g., by mobilizing previously apolitical sections of the population in a joint national-religious cause and burying an incipient liberal-clerical conflict under a single banner." Similarly, in the Russian Partition, the allure of open rebellion soon gave way to the idea of "organic work," which focused on economic and cultural independence, forging new social and economic institutions rather than overcoming the political state handed to them by Moscow (Blejwas 1982). Thus, not only did institutions come about from a previously-created identity of the Polish nation, they helped to reinforce social narratives and social identities through group reinforcement.

This institution-building, informed by identity and not pecuniary motives, provided strong informal mechanisms of resistance to occupation. However, once Poland attained independence in 1918, the shaping of formal, national political institutions remained based on a theme of persecution which no longer was the case (notwithstanding the Russo-Polish war of 1920, which brought the Bolsheviks to the shores of the Vistula River). The national identity forged under external duress, shaped by Partition, soon proved to be a huge burden in governing the newly-independent country in the interwar period. In the first instance, Poland was no longer "Polish," but a country encompassing many ethnic minorities (and where Poles were approximately only $65 \%$ of the population). The cognitive dissonance created by this reality led to sometimes extreme attempts to reconcile identity with reality, such as pervasive undercounting of minorities in Censuses of 1921 and 1931 (Hartwell 2016b) and creating a "land reform" with the explicit goal of encouraging German minorities to move back to Germany and leave Poland for the Poles (Gosewinkel and Meyer 2009). No longer a minority in their own country, Poles had 
to come to grips with the fact that they were now the dominant social group, a transition which did not come easy (Stachura 1998).

The embattled nature of Polish identity also meant that the political system was designed to replicate the Polish conception of itself during the Partitions, not necessarily as it had evolved post-1918. As Hawgood (1939:335) noted as the system was coming to an end, the first post-Partition Constitution preserved the best attributes of Polish szlachta democracy and combined "weakness in normal circumstances with strength in the face of national crisis." Indeed, following on from a long Polish history of decentralized governance and resistance to occupying authorities, a "simple majority vote" of the Sejm would be enough to force "a single minister, the whole executive cabinet, or the President to resign" (Fijalkowski 2013:38, quoting Article 58 of the Constitution). However, the unfavorable external environment which Poland faced almost immediately and the agitation of nationalists within Poland meant that a towering figure such as Marshall Josef Piłsudski was able to engineer a military coup in 1926, playing on the fears of Poles that they were perpetually in a national crisis (Hartwell 2016b). Political institutions became more and more centralized, and more on a war footing, with economic institutions delayed in favor of nation-building. Changes in the Constitution in 1935 moved Poland firmly towards a proto-fascist government and, in an unremitting irony, the identity that Poles had fashioned for themselves as persecuted minorities had resulted in the fashioning of institutions that instead brought about the destruction of the country.

In short, the actions of successive Polish governments in the interwar period call to mind Davis (2010:34), who, writing in another context, noted that "economic agents act today on expectations about an economy that they themselves expect to face tomorrow. Whether or not their expectations about the economy are fulfilled, and however the economy changes, they nonetheless act on the 
assumption that they continue as essentially who they are... when economic agents act, they act as if they retain their respective identities through time." The Polish national identity, evolving from shifting individual and group identities, became solidified in the late $18^{\text {th }}$ century and barely moved, even when exogenous circumstances demanded that it did. The lack of evolution in Polish identities meant that weak and anachronistic institutions were founded, based on an identity that bore little relation to reality. In this manner, "inefficient" institutions persisted, but were soon overcome by external factors; namely, the Great Depression, the rise of fascism, and the eventual dismemberment of the Polish state once again.

\section{Conclusions}

This paper has attempted to forge a link between the identity economics and the new institutional economics literatures, focusing on the role of identity in driving institutional formation. New institutional economics often talks about the path dependency of institutions and how they emerge out of a specific cultural and socio-economic milieu; to this insight, we can also add that identity plays a central role in setting out this path. As shown in our theoretical discussion, all facets of identity economics have a role to play in understanding institutional genesis and change, dependent mainly upon which type of institution we are considering. Overall, however, the role of identity in institutions explains why some institutions persist and others do not, even after they seem to have outlived their usefulness. This reality was illustrated above with the case of Poland in the $18^{\text {th }}$ through early $20^{\text {th }}$ centuries, where institutions became inextricably linked with identity, but where identity itself became anachronistic when circumstances changed... and thus, so too did the institutions. Persistence of institutions is linked to identity, but if identities are no longer relevant, then institutional mechanisms may not function. 
The purpose of this work has not only been to attempt to loosely join two separate strands of new economic thinking, but also to point the way towards identifying other areas in which an identity lens can be brought to bear in institutional economics. In a recent piece, Kranton (2016:405) noted that "the task at hand... is to develop the micro-foundations of identity;" as this paper has shown, there are also macro implications of identity, a task which may be more visible and easier to trace. Indeed, while identity economics continues to evolve, sixteen years on from the Akerlof and Kranton (2000) piece, so too must our thinking on institutions.

\section{REFERENCES}

Acemoglu, D. (2006). A simple model of inefficient institutions. The Scandinavian Journal of Economics, 108(4), 515-546.

Agrawal, A., \& Ostrom, E. (2001). Collective action, property rights, and decentralization in resource use in India and Nepal. Politics \& Society, 29(4), 485-514.

Ahdieh, R. (2011). Beyond Individualism in Law and Economics. Boston University Law Review, 91, 43-85.

Akerlof, G. A., \& Kranton, R. E. (2000). Economics and Identity. The Quarterly Journal of Economics, 115(3), 715-753.

(2005). Identity and the Economics of Organizations. Journal of Economic Perspectives, 19(1), 9-

32.

Barros, D.B. (2006). Home as a legal concept. Santa Clara Legal Review, 46(2), pp.255-306. 
Bisin, A., \& Verdier, T. (2001). The economics of cultural transmission and the dynamics of preferences. Journal of Economic theory, 97(2), 298-319.

Blanke, R. (1974). The Development of Loyalism in Prussian Poland, 1886-1890. The Slavonic and East European Review, 52(129), 548-565.

Blejwas, S. A. (1982). Warsaw Positivism -Patriotism Misunderstood. The Polish Review, 27(1/2), 47-54.

Boettke, P. J., Coyne, C. J., \& Leeson, P. T. (2008). Institutional stickiness and the new development economics. American Journal of Economics and Sociology, 67(2), 331-358.

Bowles, S. (1998). Endogenous preferences: The cultural consequences of markets and other economic institutions. Journal of Economic Literature, 36(1), 75-111.

Bubb, R. (2013). The evolution of property rights: State law or informal norms? Journal of Law and Economics, 56(3), 555-594.

Burke, P. J. (2006). Identity change. Social Psychology Quarterly, 69(1), 81-96.

Clague, C., Keefer, P., Knack, S., \& Olson, M. (1996). Property and contract rights in autocracies and democracies. Journal of Economic Growth, 1(2), 243-276. 
Commons, J. R. (1934). Institutional Economics. Its Place in Political Economy. London: Transactions Publishers.

Dai, S. (2016). Networks of Institutions. London: Routledge.

Davis, J.B. (2007). Akerlof and Kranton on identity in economics: inverting the analysis. Cambridge Journal of Economics, 31(3), 349-362.

(2010). Uncertainty and identity: a post Keynesian approach. Erasmus Journal for Philosophy and Economics, 3(1), 33-49.

(2011). Individuals and Identity in Economics. Cambridge: Cambridge University Press

(2015). Stratification economics and identity economics. Cambridge Journal of Economics, 39(5), 1215-1229.

Dia, M. (1996). Africa's management in the 1990s and beyond: Reconciling indigenous and transplanted institutions. Washington DC: World Bank.

Djankov, S., La Porta, R., Lopez-de-Silanes, F., \& Shleifer, A. (2003). Appropriate institutions. In World Bank (ed.), Annual World Bank Conference on Development Economics. Washington DC: World Bank, pp. 283-298. 
Empson, L. (2004). Organizational identity change: managerial regulation and member identification in an accounting firm acquisition. Accounting, Organizations and Society, 29(8), 759-781.

Fijalkowski, A. (2013). From Old Times to New Europe: The Polish Struggle for Democracy and Constitutionalism. Surrey, UK: Ashgate Publishing, Ltd.

Gibson, J. L. (1989). Understandings of justice: Institutional legitimacy, procedural justice, and political tolerance. Law and Society Review, 23(3), 469-496.

Gosewinkel, D., and Meyer, S. (2009). Citizenship, property rights and dispossession in postwar Poland (1918 and 1945). European Review of History-Revue européenne d'histoire, 16(4), pp. 575-595.

Grosfeld, I., Rodnyansky, A., \& Zhuravskaya, E. (2013). Persistent Antimarket Culture: A Legacy of the Pale of Settlement after the Holocaust. American Economic Journal: Economic Policy, 5(3), 189-226.

Guinnane, T. W. (1994). A Failed Institutional Transplant: Raiffeisen's Credit Cooperatives in Ireland, 1894-1914. Explorations in Economic History, 31(1), 38-61.

Gürerk, Ö., Irlenbusch, B., \& Rockenbach, B. (2006). The competitive advantage of sanctioning institutions. Science, 312(5770), 108-111.

Hahn, F. R. (2014). Culture, Geography, and Institutions: Empirical Evidence from Small-scale Banking. The Economic Journal, 124(577), 859-886. 
Haniffa, R., \& Hudaib, M. (2007). Exploring the ethical identity of Islamic banks via communication in annual reports. Journal of Business Ethics, 76(1), 97-116.

Hartwell, C.A. (2013). Institutional Barriers in the Transition to Market: Examining Performance and Divergence in Transition Economies. Basingstoke: Palgrave Macmillan.

(2016a). Determinants of property rights in Poland and Ukraine: the polity or politicians? Journal of Institutional Economics, First View. DOI: http://dx.doi.org/10.1017/S1744137416000175.

(2016b). Two Roads Diverge: The Transition Experience of Poland and Ukraine. Cambridge: Cambridge University Press.

Hawgood, J.A. (1939). Modern Constitutions Since 1787. New York: Macmillan and Company.

Henrich, J. (2000). Does culture matter in economic behavior? Ultimatum game bargaining among the Machiguenga of the Peruvian Amazon. American Economic Review, 90(4), 973-979.

Hoppe, H. H. (2006). The Economics and Ethics of Private Property: Studies in Political Economy and Philosophy. Auburn: Mises Institute.

Howard, J. A. (2000). Social Psychology of Identities. Annual Review of Sociology, 26(1), 367-393. 
Huettel, S. A., \& Kranton, R. E. (2012). Identity economics and the brain: uncovering the mechanisms of social conflict. Philosophical Transactions of the Royal Society of London B: Biological Sciences, 367(1589), 680-691.

Jost, J. T., Banaji, M. R., \& Nosek, B. A. (2004). A decade of system justification theory: Accumulated evidence of conscious and unconscious bolstering of the status quo. Political psychology, 25(6), 881-919.

Kranton, R. E. (2016). Identity Economics 2016 Identity Economics 2016: Where Do Social Distinctions and Norms Come From? American Economic Review, 106(5), 405-409.

Langley, P., \& Leyshon, A. (2012). Financial subjects: culture and materiality. Journal of Cultural Economy, 5(4), 369-373.

Long, N. (2001). Development Sociology: Actor Perspectives. London: Routledge.

Mach, Z. (1997). Heritage, Dream, and Anxiety: The European Identity of Poles. In Mach, Z., and Niedzwiedzki, D. (eds.), European Enlargement and Identity. Krakow: Univeristas Press, pp. 35-50.

(2007). The Roman Catholic Church in Poland and the dynamics of social identity in Polish society. In Faltin, L., and Wright, M.J. (eds.), The Religious Roots of Contemporary European Identity. London: A\&C Black Publishers, pp. 117-33.

Marx, K. (1979). A Contribution to the Critique of Political Economy. New York: International Publishers (original version published 1859). 
Meagher, K. (2005). Social capital or analytical liability? Social networks and African informal economies. Global Networks, 5(3), 217-238.

Mitchell, W. C. (1925). Quantitative analysis in economic theory. American Economic Review, 15(1), 112.

Moran, M. (2014). Identity and Capitalism. New York: Sage Publishing.

North, D. C. (1979). A framework for analyzing the state in economic history. Explorations in Economic History, 16(3), 249-259.

(1999). Dealing with a Non-Ergodic World: Institutional Economics, Property Rights, and the Global Environment. Duke Environmental Law and Policy Forum, 10(1), 1-12.

North, D. C., \& Weingast, B. R. (1989). Constitutions and commitment: the evolution of institutions governing public choice in seventeenth-century England. Journal of Economic History, 49(04), 803-832.

Ostrom, E., \& Hess, C. (2010). Private and Common Property Rights. In Bouckaert, B., and De Geest, G. (eds.), Property Law and Economics, Encyclopedia of Law and Economics, 2nd edition. London: Edward Elgar Publishing, pp. 53-106. 
Owen, A. L., \& Temesvary, J. (2015). Country Characteristics in Foreign Bank Investments and Risk Taking: The Role of Shared Culture, Common Institutions, and Geographic Proximity. International Finance, 18(2), 227-248.

Rajan, R. G. (1998). The past and future of commercial banking viewed through an incomplete contract lens. Journal of Money, Credit and Banking, 30(3), 524-550.

Roland, G. (2004). Understanding institutional change: fast-moving and slow-moving institutions. Studies in Comparative International Development, 38(4), 109-131.

Searle, J. R. (2005). What is an Institution? Journal of Institutional Economics, 1(1), 1-22.

Simon, B., \& Klandermans, B. (2001). Politicized collective identity: A social psychological analysis. American Psychologist, 56(4), 319-330.

Slater, D. (1997). Consumer Culture and Modernity. New York: Wiley.

Stachura, P. D. (1998). National identity and the ethnic minorities in early inter-war Poland. In Stachura, P.D. (ed.), Poland between the Wars, 1918-1939. Basingstoke: Palgrave Macmillan, pp. 60-86.

Stone, D.Z. (2001). The Polish-Lithuanian State, 1386-1795. Seattle: Washington University Press.

Syed, M., \& Azmitia, M. (2009). Longitudinal trajectories of ethnic identity during the college years. Journal of Research on Adolescence, 19(4), 601-624. 
Szreter, S. (2007). The right of registration: development, identity registration, and social security-a historical perspective. World Development, 35(1), 67-86.

Tabellini, G. (2010). Culture and institutions: economic development in the regions of Europe. Journal of the European Economic Association, 8(4), 677-716.

Tazbir, J. (1982). Polish National Consciousness in the 16th-18th Centuries. Acta Poloniae Historica, 46, 47-72.

Thelen, K. (2009). Institutional change in advanced political economies. British Journal of Industrial Relations, 47(3), 471-498.

Veblen, T. (1899). The Theory of the Leisure Class: An Economic Study of Institutions. New York: Macmillan.

Voigtländer, N., \& Voth, H. J. (2015). Nazi indoctrination and anti-Semitic beliefs in Germany. Proceedings of the National Academy of Sciences, 112(26), 7931-7936.

Zientara, B. (1974). Foreigners in Poland in the 10th-15th Centuries: Their Role in the Opinion of Polish Medieval Community. Acta Poloniae Historica, 29, 5-28.

\footnotetext{
' Figure 1 shows the intersection of the various levels of identity and institutions and how they are aggregated. The base level is that of the individual (the dashed square), influenced by intrinsic preferences and social
} 
networks which then forges an individual identity. The individual then carries this identity into various social groups (the solid circle), which may overlap or connect with other social groups and reinforces (or challenges) individual identities. The aggregation of these groups and their constituent identities then form what may be known as "national culture" at the country-level, which then, in turn, determines the formation of formal institutions.

ii Given that one of the characteristics of institutions is their semi-permanent nature, this assertion would also imply, like Stryker (1980), that identity is also relatively stable.

iii This paper thus harkens back to early Austrian/Mengerian theories of collective entities as being explained by individual actions (Ahdieh 2011).

iv As Hartwell (2013) notes, while some institutions may have political effects (such as property rights), this does not take away from the fact that the institution's objective is primarily economic. Similarly, some institutions may shift their sphere of operation over time, with the Roman Catholic Church being a prime example: once the dominant political institution in Europe, it is now primarily socially-oriented, albeit exercising some measure of political power in countries such as Poland.

${ }^{v}$ This does not mean that such identities are not transformed through the intersection and exposure to other individual identities, nor does it imply that individual identities remain static through absorption into a group dynamic. While an interesting area to explore, I am avoiding this debate here to merely note that individual identities necessarily inform larger, group-based identities, without specifying the functional form of those larger identities.

vi The reality of shifting identity, i.e. from worker to capitalist, may also explain why Marx's prediction that workers would rise up once they realized their exploitation has not come to pass. That is, if one does not identify themselves as a worker but as a potential capitalist, revolution is not the answer.

vii Alternately, conceptions of efficiency are altered immensely by the identity considerations which go into the formation of institutions. In the case of Hitler Youth, it was judged as "efficient" on a different set of metrics than what a non-racially-based educational and socialization organization would be. Voigtländer and Voth (2015) show just how this was the case, with Hitler Youth effective in terms of spreading a certain identity. 